\section{Linguistic theory}

Integrated Theory of Linguistic Ability. By T. G. Bever, J. J. Katz and D. T. Langendoen. Pp. 432. (Harvester: Hassocks, Sussex, UK; Crowell: New York, 1977.) £14.95.

Is linguistics an empirical science like psychology or a theoretical science like logic? Is it, indeed, a science at all? One is bound to wonder about the status of a discipline that has as many schools and schisms as a political movement.

The great revolutionary figure is, of course, Noam Chomsky, the genius of transformational grammar. In 1965, he proposed a grammar, the so-called "standard theory", which formally specifies two different levels of syntactic structure. The surface structure of a sentence segments it into such constituents as noun phrases and verb phrases; its deep structure involves the same sorts of constituents but arranges them in a way that unequivocally identifies the subject and object of the sentence and other such grammatical relations; deep structure is mapped onto surface structure by transformational rules.

Chomsky's syntactic arguments for this grammar were compelling: most of the trouble has arisen over meaning, and the past decade has seen a continuing 'revolution within the revolution'. The standard theory took the deep structure of a sentence as a blueprint for its meaning, and the surface structure of the sentence as a blueprint for its phonological interpretation. But a group of radical linguists has argued that the theory is riddled with internal contradictions : grammar should derive the surface structure of a sentence not from some syntactic intermediary such as deep structure but directly from its meaning.

An alternative and 'revisionary' group, led by Chomsky himself, has progressively developed first the "extended standard theory", which allows both deep and surface structure to contribute to meaning, and then the "revised extended standard theory", which derives meaning solely from surface structure. There are still other alternatives, not to mention the numerous groups of linguists working outside the framework of transformational grammar.

The editors of this book-for it is a book of readings rather than the integrated text that its title page might suggest-are members of the 'revolutionary old guard' who wish to defend the standard theory, which they con-

sider to have been abandoned prematurely. To this end they have pulled together fourteen papers, most of which are by the editors and their collaborators, and most of which have appeared in print before.

The gist of their argument is that many of the phenomena that have seemed to motivate counter-revolutionary developments, in fact, defy linguistic explanation. Rather they are to be explained on the basis of the psychology of speech perception or pragmatic conventions governing conversation. The argument is remarkably persuasive, but its effect on the status of linguistics

\section{3-D imaging techniques}

Three Dimensional Imaging Techniques. By T. Okoshi. Pp. 403. (Academic: New York and London, 1976.) $\$ 15.00 ; £ 10.65$.

INVENTORS have been fascinated by the problem of binocular or three dimensional (3-D) imaging for many years; G. della Porta (1540-1615) is reported to have drawn stereo pairs, but Wheatstone was probably the first to make a stereoscope. Since Wheatstone's time, many instruments and systems for producing 3-D images have been invented, several of them described in this book, but it must be admitted that none has yet proved to be the solution to become popular and make its backers multimillionaires.

In this book, there are chapters on vision (a brief treatment stressing depth perception), lens-sheet 3-D pictures (that is, pictures seen through lenticular screens, as in picture postcards and, about 25 years ago, in advertisements on the London underground), projection displays (the various devices for cine projection of 3-D pictures) and, of course, holography. Then there is a chapter on the information content of the different forms of 3-D imagery, and finally a chapter for unclassifiable systems; some of these are connected with computer-generated images and others, such as Gabor's cine projection screen in the form of a gigantic volume hologram, are unlikely to be realised in the foreseeable future. Notable omissions are the cine techniques popular in the early 1950s in which stereo pairs were projected on a single screen either in different colours, to be viewed through appropriately coloured spectacles, or in orthogonal polarisations, to be viewed through polarising spec- is more questionable. Where many theories compete, it is natural to attempt to confront them with a wider set of empirical phenomena. By deliberately diminishing the set of relevant phenomena, the authors might seem to be moving linguistics towards the threshold of the comfortably insulated world of parlour politics.

\section{P. N. Johnson-Laird}

P. N. Johnson-Laird is Reader in Experimental Psychology at the University of Sussex, UK.

tacles; there is also no mention of the Land Vectograph, a polarisation system used for producing prints or transparencies to be viewed through polarisers.

This book is at its best in the explanations of the technical details of the systems, and this is as it should be since the subject really depends on inventive developments. It is less impressive on the physical principles; for example, in the chapter on information a table gives the bandwidths required to transmit 3-D television by different methods, and figures of order $10^{12} \mathrm{~Hz}$ are given for wide-view holography; however, there are no comments on the prospects for achieving such a bandwidth and there is no indication of how the holographic image might be reconstructed. Much of the discussion in the chapter on information is aimed at television transmission but since this is probably many years ahead it is unlikely that the chapter will be very useful. Thus, the book is really an inventor's compendium or review on the subject and it is very good of its kind. Some of the practical details about lasers and holography are outof-date, but this is because the book was originally published in 1972 (in Japanese). The present translation is very competently done by the author.

One may ask after reading Okoshi whether there will ever be a really good system for showing 3-D images? Perhaps not, although it is risky to prophesy; however, there is another method not mentioned by Okoshi, but known to and practised by the ancient Greeks, which gives quite good results - sculpture. Perhaps it will find a place among the Alternative Technologies.

\section{W. T. Welford}

W. T. Welford is Professor of Physics working in the Optics Section of the Blackett Laboratory, Imperial College, University of London, UK. 